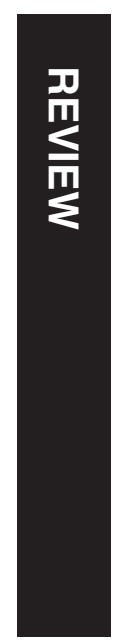

\section{A review of anti-VEGF agents for proliferative diabetic retinopathy}

1 Department of Ophthalmology, Soroka University Medical Center, Ben-Gurion University of the Negev, Beer-Sheva, Israel

${ }^{2}$ Medical Retina Unit, Royal Victorian Eye and Ear Hospital; Centre for Eye Research Australia, University of Melbourne, Melbourne, Victoria, Australia

Correspondence: J Levy, Department of Ophthalmology, Soroka University Medical Center, P.O. Box 151, Beer-Sheva 84101, Israel

Tel: + 97286400379 ; Fax: + 97286275712

E-mail: ljaime@bgu.ac.il

Received: 10 October 2013 Accepted in revised form: 18 December 2013 Published online: 14 February 2014

\begin{abstract}
Previous research has implicated vascular endothelial growth factor (VEGF) in the pathogenesis of diabetic retinopathy (DR). Although many studies reviewed the use of anti-VEGF for diabetic macular oedema, little has been written about the use of anti-VEGF for proliferative diabetic retinopathy (PDR). This study is a review of relevant publications dealing with the use of anti-VEGF for the treatment of PDR. The articles were identified through systematic searches of PUBMED and the Cochrane Central Register of Controlled Trials. At the end of each section, we summarized the level of evidence of the scientific literature. Off-label use of anti-VEGF agents was found to be beneficial in PDR, especially in cases with neovascular glaucoma, persistent vitreous haemorrhage, and before vitrectomy. The disadvantages of the use of anti-VEGF are its short-effect duration, causing tractional retinal detachment in cases with pre-existing pre-retinal fibrosis and endophthalmitis in rare cases. There is no conclusive evidence from large randomized trials regarding the efficacy of anti-VEGF treatment in PDR. However, numerous case series, sound biochemical mechanism of action, and increasing experience with using anti-VEGF drugs can be used to support the ongoing use of this treatment modality in selected patients. Eye (2014) 28, 510-520; doi:10.1038/eye.2014.13; published online 14 February 2014

Keywords: diabetic retinopathy; proliferative diabetic retinopathy; panretinal photocoagulation; ranibizumab; Bevacizumab; vascular endothelial growth factor
\end{abstract}

\section{Introduction}

Proliferative diabetic retinopathy (PDR) is a major cause of blindness. Approximately, 1.5\% of adults with diabetes have PDR. ${ }^{1}$ The Diabetic Retinopathy Study showed that about half of all eyes with PDR that are left untreated will have severe vision loss (ie, visual acuity of $<20 / 800$ for at least 4 months). ${ }^{2}$

PDR is characterized by retinal neovascularization, serum leakage, haemorrhage, and fibrovascular proliferation in the vitreous retinal interface, which further results in vitreous haemorrhage and traction retinal detachment. ${ }^{3}$

The pro-angiogenic cytokine vascular endothelial growth factor (VEGF) is considered the primary factor involved in neovascularization in PDR. ${ }^{4}$ In the base of PDR pathophysiology stands angiogenesis. ${ }^{5} \mathrm{~A}$ key player in this process is VEGF. ${ }^{6,7}$ Increased levels of VEGF have been reported in the vitreous humour and in fibrovascular tissues from eyes with PDR. ${ }^{8-13}$ VEGF activates two tyrosine kinase receptors, VEGFR-1 and VEGFR-2. These receptors regulate physiological and pathological angiogenesis. VEGFR-2 is expressed mostly on vascular endothelial cells. ${ }^{14}$ Activation of VEGFR-2 stimulates endothelial cell proliferation, migration, and survival, as well as angiogenesis and microvascular permeability as in PDR. ${ }^{14}$

Until recent years, panretinal photocoagulation (PRP) was the first and only choice for treating PDR. For PDR with high-risk characteristics, the Diabetic Retinopathy Study (DRS) showed a $>50 \%$ decrease in the rate of severe vision loss when PRP was executed. ${ }^{15}$ When new vessels respond to PRP by regressing within the first 3 months after treatment, the visual outcome tends to be excellent. ${ }^{16}$ Although proven beneficial, PRP had its own complications, such as pain during treatment, loss of peripheral vision, nyctalopia, uveal effusions, worsening of macular oedema, vitreous haemorrhage and difficulty in treating eyes with vitreous haemorrhage, and advanced 
cataract. ${ }^{16-19}$ These complications brought the need for new modalities in treating PDR, such as anti-VEGF. This review will summarize the literature on anti-VEGF in treating PDR.

\section{Ant1-VEGF drugs}

1. Bevacizumab (Avastin; Genentech, San Francisco, CA, USA) is a full-length recombinant humanized anti-VEGF monoclonal antibody, approved by the US Food and Drug Administration for the treatment of colorectal cancer. ${ }^{20}$ It is a large-sized molecule (molecular weight: $148 \mathrm{kDa}$ ) and has twice half-life than ranibizumab. ${ }^{21}$

2. Ranibizumab (Lucentis; Genentech USA, Inc., San Francisco, CA, USA/Novartis Ophthalmics, Basel, Switzerland) is an engineered, humanized, recombinant antibody fragment (Fab) active against all VEGF-A isoforms. It lacks the Fc domain and has a shorter halflife than other anti-VEGF agents. ${ }^{22}$ Lucentis is presently licensed (FDA approved) as an intravitreal agent for the treatment of wet, age-related macular degeneration (AMD).

3. Pegaptanib (Macugen, Eyetech Inc., Cedar Knolls, NJ, USA) is a 28-nucleotide RNA aptamer that binds specifically to the VEGF-A165 isomer, the major pathological VEGF protein in the eye.

4. Aflibercept (Regeneron, Tarrytown, NY, USA) with trade name Eylea (also known as VEGF Trap-Eye), is a recombinant fusion protein comprising the key VEGFbinding domains of human VEGF receptors 1 and 2 . Aflibercept was found to bind VEGF with a greater affinity than that of bevacizumab or ranibizumab. ${ }^{23}$ The FDA approved aflibercept as a therapy for neovascular AMD in 2011.

\section{Materials and methods}

The authors performed comprehensive searches for published studies through August 2013 that evaluated the effects of anti-VEGF agents on PDR by using electronic databases, such as PUBMED and the Cochrane Central Register of Controlled Trials. Reference lists from identified studies and key review articles dealing with the effects of anti-VEGF agents for PDR treatment were searched. The search was restricted to English-language articles. Search terms used were 'proliferative diabetic retinopathy', 'retinal neovascularization', 'vitreous haemorrhage', 'neovascular glaucoma', 'anti-vascular endothelial growth factor', 'vascular endothelial growth factor', 'Macugen', 'pegaptanib', 'bevacizumab', 'Avastin', 'Lucentis', and 'ranibizumab' in various combinations. The authors independently identified and grouped the studies before these data were concluded. Relevant articles that were cited in the reference lists of the retrieved articles were also included. Articles considered irrelevant to PDR and duplicate studies were excluded. Levels of evidence are based on the National Health and Medical Research Council of Australia (Table 1). ${ }^{24}$

\section{Anti-VEGF treatment and safety}

Dosage and frequency of anti-VEGF treatment in PDR cases The optimal dose and dosing sequence for bevacizumab remains unclear. Most studies have used a dose of 1.25 mg. $^{25-29}$ Arevalo and Garcia-Amaris ${ }^{30}$ used dosages of $1.25 \mathrm{mg}$ (20.5\%) and $2.5 \mathrm{mg}$ (79.5\%) bevacizumab, depending on the discretion of the treating clinician, and noted that the $2.5-\mathrm{mg}$ dose was more effective in inducing complete regression of neovascularization relative to the $1.25-\mathrm{mg}$ dose in the treatment of naive eyes.

In contrast, Avery et al ${ }^{31,32}$ reported no significant differences between the effects of various doses of bevacizumab, ranging from $6.2 \mu \mathrm{g}$ to $1.25 \mathrm{mg}$, on retinal neovascularization. However, they hypothesized that durability of the drug effect may vary, with higher doses producing a longer duration of effect. Hattori et al ${ }^{33}$ showed that the lowest dose tested $(0.16 \mathrm{mg})$ of intravitreal bevacizumab (IVB), as a preoperative adjunct therapy to patients before undergoing vitrectomy for PDR, was as effective as the standard dose $(1.25 \mathrm{mg})$

Table 1 National Health and Medical Research Council hierarchy of evidence-based scientific studies

\begin{tabular}{|c|c|}
\hline Level & Intervention \\
\hline I & A systematic review of level II studies \\
\hline II & A randomized controlled trial \\
\hline III-1 & $\begin{array}{l}\text { A pseudorandomized controlled trial (ie, alternate } \\
\text { allocation or some other method) }\end{array}$ \\
\hline III-2 & $\begin{array}{l}\text { A comparative study with concurrent controls: } \\
\text { Non-randomized experimental trial } \\
\text { Cohort study } \\
\text { Case-control study } \\
\text { Interrupted time series with a control group }\end{array}$ \\
\hline III-3 & $\begin{array}{l}\text { A comparative study without concurrent controls } \\
\text { Historical control study } \\
\text { Two or more single-arm study } \\
\text { Interrupted time series without a parallel control group }\end{array}$ \\
\hline IV & $\begin{array}{l}\text { Case series with either post-test or pretest/post-test } \\
\text { outcomes }\end{array}$ \\
\hline
\end{tabular}


in reducing vitreous VEGF concentrations and also decreasing intraoperative bleeding as measured by the reduced number of coagulation spots.

Arevalo et $a^{34}$ reported no difference in outcomes between IVB at doses of 1.25 and $2.5 \mathrm{mg}$ on central macular thickness and best-corrected visual acuity (BCVA) in patients with diabetic macular oedema (DME; 41.7\% with PDR).

Concerns have been raised about increasing the foveal avascular zone (FAZ) with repeated IVB injections or the use of higher-dose injections $(2.5 \mathrm{mg}),{ }^{35}$ although these concerns have not been proven (see below discussion). Likewise, the frequency of bevacizumab for these indications remains unclear. Most studies deferred re-injections to cases that only showed recurrence. ${ }^{30}$

Effectiveness of dose $1.25 \mathrm{mg}$ bevacizumab at regression of neovascularization: level of evidence IV.

Rate of regression and recurrence of retinal neovascularization All anti-VEGF agents have shown promising results with regard to the regression of neovascularization, but they were limited by their short duration. None of the agents can substitute for the remarkable durability of PRP that qualifies it as the gold standard treatment for PDR.

The average time to recurrence of retinal neovascularization following anti-VEGF treatment ranges from 1 week $^{27}$ to 3 months. ${ }^{29,31,36}$ Persistence of the effect of treatment 6 months post injection appears to be a standard average end point for evaluating the effectiveness of anti-VEGF treatments. Unfortunately, very few of the studies included a 6-month follow-up. In an interventional prospective case series on IVB in active PDR at the baseline examination, five eyes had iris neovascularization (NVI); 1 week after the first injection only two eyes had NVI. No cases of NVI were detected at week 6, but two cases were seen at week 12 , one was a recurrence and the other was a new case. ${ }^{37}$

Over a 28-week period following bevacizumab treatment, Arevalo and Garcia-Amaris ${ }^{30}$ reported that $61.4 \%$ of patients showed complete regression without fluorescein leakage, $34 \%$ of patients showed a partial regression, and $4.5 \%$ of patients showed no regression of neovascularization. Mendrinos et $a l^{38}$ reported the complete regression of neovascularization 1 year after a single injection of pegaptanib in a patient with previous PRP.

In a retrospective analysis of 16 patients with PDR, Adamis $e t a l^{39}$ reported a possible persistent beneficial effect with intravitreal pegaptanib, with $62 \%$ of the treated eyes $(n=13)$ showing regression or a lack of neovascularization at the 6-month follow-up visit; however, the mean number of injections was 5 (range: 3-6), and only one patient had high-risk PDR.

Minnella et $a l^{40}$ reported that the early effects of bevacizumab were maintained at 3 months in 15 injected eyes. Likewise, Schmidinger et al ${ }^{41}$ reported that $62 \%$

(8 of 13) of eyes required retreatment with bevacizumab at a 3-month follow-up visit because of the reappearance of new vessels. In another study, Mishahi et al ${ }^{28}$ showed complete regression in $87.5 \%$ of Avastin-injected eyes and $25 \%$ of sham group at week 6 of follow-up $(P<0.005)$. However, at week 16, PDR recurred in a sizable number of the Avastin-treated eyes, and the complete regression rate in the two groups became identical $(25 \% ; P=1.000)$.

In summary, these studies showed that intravitreal anti-VEGF can cause regression of neovascularization secondary to PDR. In spite of its short duration compared with PRP, even a transient effect could be of benefit in a variety of clinical settings, such as in the presence of media opacity precluding PRP, rubeosis yet to cause angle closure, or as a preoperative surgical adjuvant.

An average rate of retinal neovascularization regression of 6 weeks and recurrence at 16 weeks after one Avastin injection in PDR patient: level of evidence II.

\section{Adverse effects}

Local adverse effects of anti-VEGF

Tractional retinal detachment (TRD): In patients with severe PDR, bevacizumab can cause TRD. ${ }^{42}$ The contraction of this fibrous tissue can cause TRD and vitreous haemorrhage. ${ }^{43,44}$ Other presumed mechanisms include the extreme fluctuations in intraocular pressure (IOP) and deformation of the globe during intravitreal injection, resulting in vitreoretinal traction. ${ }^{43,45,46}$

Another possible mechanism is the angio-fibrotic switch of VEGF and connective tissue growth factor (CTGF) in PDR. The anti-VEGF intravitreal injection reduces intravitreal unbound, active VEGF levels. This can cause rising CTGF levels and thus promote a switch from angiogenesis to fibrosis. ${ }^{47}$ Arevalo et al ${ }^{45}$ reported that $82 \%$ of TRD developed within 5 days of injection. The highest incidence of progression of pre-existing TRD has been reported as $18 \%$ over a $2-30$-day period. ${ }^{48}$ The only reported case of TRD after pegaptanib to date was reported after an interval of 3-5 weeks following intravitreal treatment. ${ }^{49}$

Risk factors for TRD following bevacizumab include a longer time interval between bevacizumab injection and vitrectomy in patients with uncontrolled diabetes, vitreous haemorrhage, and PDR resistant to PRP. ${ }^{43,50}$ In a retrospective, multicentre, interventional, comparative case series on IVB for PDR, the risk factors for TRD after IVB were time from diagnosis of DM of $>15$ years, time 
interval from IVB to vitrectomy of $>13$ days, and the use of the higher dose of IVB $(2.5 \mathrm{mg}) .^{51}$

Risk factors for TRD after IVB in PDR patient (level of evidence III-2):

- Time from diagnosis of DM of >15 years,

- Uncontrolled diabetes,

- Vitreous haemorrhage,

- PDR resistant to PRP time interval from IVB to vitrectomy of $>13$ days, and

- The use of the higher dose of IVB (2.5 mg).

FAZ enlargement: Development of macular ischaemia following IVB has been reported in single case reports. ${ }^{35,52}$ Lee and $\mathrm{Koh}^{35}$ reported angiographically a FAZ enlargement following pars plana vitrectomy and treatment with $2.5 \mathrm{mg}$ bevacizumab. ${ }^{35}$

However, macular perfusion was assessed in a prospective randomized, single-centre 2-year trial comparing $1.25 \mathrm{mg}$ IVB (42 eyes) and laser therapy (38 eyes) in patients with diabetic macular edema. ${ }^{53}$ At baseline, the mean greatest linear dimension of the FAZ in the laser group was $685 \pm 262$ microns and in the bevacizumab group it was $737 \pm 262$ microns. There was no significant difference at the 4-month time point $(P=0.40)$, with the mean greatest linear dimension of the FAZ in the laser group recorded as $678 \pm 221$ microns and in the bevacizumab group $678 \pm 231$ microns. It was concluded that at 4 months there was no evidence of worsening macular ischaemia in either group.

No evidence of development of macular ischaemia following IVB: level of evidence II.

Rise in IOP: IOP elevation following an intravitreal injection can be explained by several mechanisms. A major cause is a temporary vitreous volume increase causes an IOP spike. Studies with pegaptanib have shown such a spike normalizes within $1 \mathrm{~h} .{ }^{54}$ One of the other possible reasons for the raised IOP after IVB includes blockage of the trabecular meshwork by bevacizumab, which is a large $148-\mathrm{kDa}$ protein. ${ }^{46}$ The frequency of transient IOP rise after bevacizumab was reported as $0.16 \% .^{55}$

Temporary increase in IOP following IVB injection: level of evidence IV.

Macular hole: Bevacizumab can cause rapid neovascular involution with accelerated fibrosis, posterior hyaloid contraction, and macular retinal detachment. Macular hole has been reported after bevacizumab in pars plana vitrectomy in diabetic eyes although macular hole can develop during the natural course of PDR or after vitrectomy alone. ${ }^{56,57}$
Macular hole formation after bevacizumab in diabetic patient: level of evidence IV.

Other local side effects: Other side effects of bevacizumab include uveitis particularly at higher doses, with a reported incidence of $0.09-1.9 \% .^{54,58}$

Although VEGF has been implicated in pathological ocular neovascular disease, endogenous VEGF is very important in the maintenance and survival of retinal neurons, Muller cell, and photoreceptors of the adult retina. ${ }^{59-62}$ This requires judicious use of long-term intravitreal anti-VEGF therapies, as they may have deleterious effects on these cells.

Other serious ocular side effects, which are general side effects from intravitreal anti-VEGF injection in general, include endophthalmitis (range in the literature $0.019-0.09 \%) .{ }^{63}$ In the DRCRNe. ${ }^{64}$ on DME patient, the rate of endophthalmitis was $0.4 \%$ per injection while in the MARINA ${ }^{65}$ and CATT $^{66}$ trails on AMD patients the rate of endophthalmitis per injection was 0.05 and $0.7-1.2 \%$, respectively.

Endophthalmitis risk of $0.05 \%-1.2 \%$ per injection: level of evidence II.

Systemic adverse effects of anti-VEGF Further studies are needed to verify the systemic side effects of antiVEGF agents, especially in diabetic patients with significant vascular comorbidities. Among the systemic side effects, the most common is hypertension (for at least 6 weeks after the injection), followed by other cardiovascular complications. ${ }^{67,68}$

The largest data set for bevacizumab treatment is presently represented by a retrospective study of 1173 patients who received IVB for DME and were followed up for 12 months. A number of adverse effects were reported: 7 cases of acute elevation of blood pressure $(0.4 \%), 6$ strokes, 5 myocardial infarctions, and 5 deaths. ${ }^{53}$ In the RISE and RIDE studies on the effect of monthly 0.5 or $0.3 \mathrm{mg}$ ranibizumab or sham injection on DME patients, after 36 months of follow-up the rate of stroke was higher in the $0.5 \mathrm{mg}$ group (12 (4.8\%)) compared with the $0.3 \mathrm{mg}$ group $(5(2.0 \%))$ or sham $/ 0.5 \mathrm{mg}$ group $(6(2.4 \%))$. The incidence of myocardial infarction through month 36 was 18 (7.2\%) in the $0.3 \mathrm{mg}$ group and $9(3.6 \%)$ in the $0.5 \mathrm{mg}$ group. ${ }^{69}$ In the DRCRNet study, there were no difference in systemic adverse events among the three groups; however, there were $4(4 \%)$ cardiovascular or cerebrovascular events in the sham group compared with $8(7 \%)$ in the ranibizumab group $(P=0.33)$ and $4(3 \%)$ in the triamcinolone group $(P=0.86) .{ }^{64}$ Larger data sets exist for patients with AMD, but these are very different patient groups demographically and clinically. Increased rates of vascular events were detected in the 
ranibizumab-treated patients (2.1\% myocardial infarction and stroke) compared with the control group (1.1\%). (Lucentis (Ranibizumab injection) Package Insert, Genentech Corporation.) The VISION trial performed in patients with neovascular AMD treated with intravitreal pegaptanib reported no systemic side effects. ${ }^{70,71}$ The CATT Research Group compared between ranibizumab and bevacizumab for neovascular AMD, with its limited statistical power to detect important adverse events, found no significant differences between the two drugs in rates of death, arteriothrombotic events, or venous thrombotic events. However, the rate of serious systemic adverse events, primarily hospitalizations, was higher among bevacizumab-treated patients than among ranibizumab-treated patients (24.1 vs 19.0\%, $P=0.04){ }^{66}$

In contrast, Campbell et $a l^{72}$ looked retrospectively at population data and could not detect an increased risk. However, this AMD data may not be applicable in younger diabetic patients who may have significant vascular comorbidities.

It is therefore essential before starting the treatment to explain to the patients about the possible systemic side effects of intravitreal injections of anti-VEGF.

Increased risk of elevation of blood pressure, stroke, and myocardial infarctions after IVB in patient with DME: level of evidence $I V$.

\section{Indications of anti-VEGF treatment for PDR}

Neovascular glaucoma (NVG) NVG in PDR occurs as a result of posterior segment ischaemia with abundant VEGF. A pilot trial on 26 eyes with NVG (73\% secondary to PDR) was performed by Costagliola et al. ${ }^{73}$ At the end of the treatment, which included three IVB injections 1 month apart, it was possible to evaluate a regression of neovascularization paralleled by an IOP ranging from 0 to $30 \mathrm{~mm} \mathrm{Hg}$ (mean: $13 \mathrm{~mm} \mathrm{Hg}$ ). However, after 1 year of follow-up, 14 patients were treated with standard glaucoma medication, and three eyes required glaucoma valve implants. Chalam et $a l^{74}$ showed complete regression of neovascularization due to aggressive NVG (69\% secondary to PDR) within 3 weeks from the treatment with intracameral bevacizumab. Lim et $a l^{75}$ showed a massive regression of iris neovascularization and a significant reduction in intravitreal VEGF levels in a 2-week period, and no significant changes in IOP in NVG patients treated with intracameral bevacizumab. Eid et $\mathrm{al}^{76}$ demonstrated that combining PRP with bevacizumab ablated the ischaemic retina and ensured good success rates in patients with intractable glaucoma requiring shunt procedures. In this study, 10 eyes were injected with bevacizumab 1-2 weeks before surgery, followed by PRP; a further 10 eyes were used as control group with PRP performed only preoperatively. Over a 1-year follow-up, the mean IOP decreases were 18.8 and $15.9 \mathrm{~mm} \mathrm{Hg}$ with success rates of 85 and $70 \%$ in the bevacizumab and control groups, respectively. It was postulated that the anti-VEGF treatment provided rapid regression of neovascularization and a therapeutic window of time in which to apply the more permanent thermal laser ablation of ischaemic retina.

It has been proposed that if bevacizumab is administered when the anterior chamber angle is still open, before the formation of peripheral anterior synechiae and angle closure, surgical interventions are more likely to be avoided than when it is administered at a later stage.

Regression of iris neovascularization and no significant changes in IOP in NVG patients treated with intracameral bevacizumab: level of evidence III-3.

Vitreous haemorrhage $(\mathrm{VH}) \mathrm{VH}$ is a common complication of PDR. The obscure fundus makes it difficult to monitor the course of the disease and could result in delayed management of possible retinal detachments or additional application of laser treatment. Anti-VEGF agents reduce the time required for vitreous clear-up and decrease the need for vitrectomy. ${ }^{77,78}$ In most cases, bevacizumab was injected 1 week before the vitrectomy in order to avoid TRD in cases of severe PDR as discussed above. ${ }^{37,45}$

In a recent study by the Diabetic Retinopathy Clinical Research Network, the benefit of intravitreal ranibizumab was compared with intravitreal saline injections on vitrectomy rates for vitreous haemorrhage from PDR. ${ }^{79}$ Their study on 261 participants showed a cumulative probability of vitrectomy by 16 weeks lower than expected in both groups, $12 \%$ with ranibizumab vs $17 \%$ with saline. These findings suggest little benefit to ranibizumab over saline, and there was no sham injection arm to compare. The secondary outcomes, such as better visual acuity, fewer recurrent vitreous haemorrhages, and increased chance of completing PRP, suggest at least a short-term biological effect of intravitreal ranibizumab compared with intravitreal saline. No increased risk of TRD was found.

Little benefit to ranibizumab over saline in decreasing the need for vitrectomy in PDR patient with VH: level of evidence II.

Short-term biological effect of intravitreal ranibizumab on visual acuity, fewer recurrent vitreous haemorrhages, and increased chance of completing PRP in PDR patient with VH: level of evidence II.

Intravitreal injection of anti-VEGF agents reduce the time required for vitreous clear-up: level of evidence IV. 
Preoperative surgical adjunctive treatment Bevacizumab has been suggested to reduce intraoperative and postoperative bleeding when used before the vitrectomy. ${ }^{43,50,80}$ Yeh et al ${ }^{43}$ examined 41 eyes with severe PDR and gave half of them bevacizumab and the other half placebo 1 week before the vitrectomy. Even though intraoperative subretinal haemorrhage was more frequent in the bevacizumab group, the intraoperative bleeding was significantly worse in the placebo group. In another study, Rizzo et $a l^{25}$ randomized 22 eyes with severe PDR and TRD either to IVB or to sham injection 5-7 days before vitrectomy. They showed that complication in the surgical procedure (which was evaluated by recording operative times, number of instrument exchanges, number and severity of intraoperative bleeds, dissection techniques, and intraoperative retinal tears) were reduced in the bevacizumab group. Ahmadieh et $a l^{50}$ enrolled 68 eyes scheduled to undergo vitrectomy for PDR. They randomized half to IVB and half to sham injection 1 week before vitrectomy. Only 34 eyes completed the study, as patients who were treated with bevacizumab showed a significant improvement after the injection. Intraoperative bleeding, post-vitrectomy haemorrhage, and the use of intraoperative endodiathermy were significantly lower in the group treated with bevacizumab compared with the placebo group.

In the Cochrane review on anti-VEGF for prevention of postoperative vitreous cavity haemorrhage after vitrectomy $(\mathrm{POVCH})$ for PDR, the results suggest that the rate of early ( $<3$ weeks) $\mathrm{POVCH}$ is reduced following administration of preoperative IVB, and BCVA was improved 6 months after surgery. ${ }^{81}$ The data was inconclusive regarding the benefit of IVB on revision vitrectomy after 6 months and density of the POVCH. Regarding adverse effect, they found a small risk of TRD and increased macular ischaemia.

In contrast to the above results, Ahn et al ${ }^{82}$ assessed the effects of preoperative and intraoperative IVB injection on the incidence of postoperative vitreous haemorrhage after vitrectomy for PDR in 107 eyes. Cases were assigned randomly to group 1 (intravitreal $1.25 \mathrm{mg}$ / $0.05 \mathrm{ml}$ bevacizumab injection 1-14 days before PPV), group 2 (intravitreal $1.25 \mathrm{mg} / 0.05 \mathrm{ml}$ bevacizumab injection at the end of PPV), or group 3 (no IVB injection). The incidences of early ( $\leq 4$ weeks) recurrent $\mathrm{VH}$ were $22.2,10.8$, and $32.4 \%$ in groups 1,2 , and 3 , respectively $(P=0.087)$. The incidences of late $(>4$ weeks) recurrent $\mathrm{VH}$ were $11.1,16.2$, and $14.7 \%$ in groups 1,2 , and 3 , respectively $(P=0.813)$. The initial time of vitreous clearing (ITVC) in groups 1,2 , and 3 were $26.4 \pm 42.5$, $10.3 \pm 8.2$, and $25.2 \pm 26.1$ days, respectively. The BCVA at 6 months after surgery did not differ significantly among the three groups $(P=0.418)$. In summary, the authors did not find substantial evidence to support the adjunctive use of preoperative IVB to reduce postoperative recurrence of $\mathrm{VH}$ in vitrectomy for PDR.

In contrast, a meta-analysis of six randomized controlled trials (published before the study by Ahn et $a l^{82}$ ) and one comparative study on clinical outcomes of vitrectomy with or without IVB pre-treatment for severe diabetic retinopathy, there was a great benefit to the use of bevacizumab. ${ }^{83}$ The surgical time was shorter in the IVB pre-treatment group $(P<0.01)$. Postoperative results showed great promise with shorter absorption of blood $(P=0.04)$, significantly less incidence of recurrent VH $(P=0.05)$, and a better final BCVA $(P=0.003)$ in the IVB group than in the control group. Complications, including final retinal detachment, and reoperation, were statistically insignificant.

In conclusion, according to the recent research, preoperative IVB has likely benefit for PDR, but randomized controlled trials with larger sample sizes and a long follow-up time are needed to better evaluate the long-term benefits and safety of bevacizumab pretreatment for severe PDR.

$I V B$ in eyes with PDR before vitrectomy reduced surgical time, postoperative vitreous cavity haemorrhage and improved $B C V A$ : level of evidence I.

$I V B$ in eyes with PDR before vitrectomy reduced number of instrument exchanges, number and severity of intraoperative bleeds, dissection techniques, and intraoperative retinal tears: level of evidence II.

DME Patients with PDR in many cases have DME. Although PRP can reduce the risk of severe visual loss in patients with high-risk PDR, ${ }^{17,84}$ a potential exists for exacerbation of macular oedema. ${ }^{85-87}$ The ETDRS results demonstrate that, for eyes with macular oedema, focal photocoagulation is effective in reducing the risk of moderate visual loss but that scatter photocoagulation is not. ${ }^{84}$ The Diabetic Retinopathy Clinical Network conducted a phase 3 , randomized, multicentre, clinical trial with 345 eyes with a visual acuity of 20/320 or better, centre-involved DME receiving focal/grid laser, and diabetic retinopathy receiving PRP. Patients were randomly assigned to sham, $0.5 \mathrm{mg}$ ranibizumab at baseline and 4 weeks, or $4 \mathrm{mg}$ triamcinolone at baseline and sham at 4 weeks. Mean changes $( \pm S D)$ in visual acuity letter score from baseline were significantly better in the ranibizumab $(+1 \pm 11 ; P<0.001)$ and triamcinolone $(+2 \pm 11 ; P<0.001)$ groups compared with those in the sham group $(-4 \pm 14)$ at the 14 -week visit, mirroring retinal thickening results. These findings emphasize the role of ranibizumab in reducing the risk of short-term exacerbation of macular edema and associated visual acuity loss following PRP. These differences were not maintained after 56 weeks, as the 
study was not designed to evaluate the effectiveness of any treatment after the 14-week study visit and only for long-term safety information. One eye $(0.9 \% ; 95 \%$ confidence interval, $0.02-4.7 \%$ ) developed endophthalmitis after receiving ranibizumab. ${ }^{64}$

Filho et $a l^{88}$ and Cho et al ${ }^{89}$ compared PRP alone with PRP and ranibizumab or bevacizumab, respectively, for patients with high-risk PDR. In these studies, the adjunctive use of ranibizumab/bevacizumab protected against the macular swelling observed in eyes treated with PRP alone.

Ranibizumab injection before PRP treatment in patient with $D M E$ reduced the risk of short-term exacerbation of macular edema and associated visual acuity loss: level of evidence II.

Active PDR resistant to PRP PRP is currently the standard treatment for PDR. ${ }^{15}$ Inspite of its success in prevention and even regression in already developed $\mathrm{NV}$, some NV show no regress or even progress in size, ${ }^{16}$ many patients require additional laser treatment, and $4.5 \%$ undergo pars plana vitrectomy despite PRP. ${ }^{90}$ Erdol et $a l^{91}$ in their study of 33 eyes of 24 patients with persistent NV in PDR after PRP found that after only one intravitreal injection of 1.25 of bevacizumab complete resolution rate was $78.8 \%$ at 1 month, $63.6 \%$ at 3 months, and $45.4 \%$ at 6 months. Cintra et al ${ }^{92}$ followed up for 1 year diabetic patients with actively leaking NV refractory to PRP who been treated with $1.5 \mathrm{mg}$ of IVB. In their study of 12 patients with persistent NV, BCVA improved from $0.90 \pm 0.11$ at baseline to $0.70 \pm 0.12$ at week 48 $(P=0.0449)$. Throughout the 48 -week study period, patients received a mean of 2.16 injections. Mean fluorescein leakage was $27.7 \pm 6.2 \mathrm{~mm}^{2}$ at baseline and was significantly lower at all visits post injection; at week 6 , no leakage was observed $(P=0.0001)$. Moradian et al $^{37}$ evaluated the effect of bevacizumab for eyes with active progressive PDR not responsive to PRP. Bevacizumab was given to 38 eyes at baseline and after 6 or 12 weeks according to the protocol. The end point was defined as regression of active fibrovascular tissue and resolution of vitreous haemorrhage. At 6 weeks, the vitreous haemorrhage resolution was significant $(P=0.06)$, with no significant effect on fibrovascular tissue. The negative side effect, as mentioned above, was that $5.3 \%$ of eyes developed TRD.

Jorge et al ${ }^{93}$ reported on 15 eyes with persistent, active PDR in which one injection of bevacizumab was administered. At the 12-week follow-up, fluorescein leakage was improved, with no significant adverse events. BCVA was improved significantly from baseline at all time points (1, 6, and 12 weeks), from 20/160 at baseline to approximately 20/125 at 12 weeks.
These studies show that IVB decreases leakage from diabetic neovascular lesions in persistent, active PDR. Further studies are needed, particularly on long-time side effects, in order to translate these research findings into clinical guidelines.

Bevacizumab injection induced regression of persistent $N V$ after PRP, improves BCVA, and decreases fluorescein leakage: level of evidence III-2.

\section{Combination treatments}

Treatment combination of anti-VEGF and conventional treatment for PDR (PRP) has been reported in a few case series. $^{25-27,94-96}$

Filho et $a l^{88}$ conducted a prospective study on PRP alone compared with PRP and ranibizumab for patients with high-risk PDR. One group was treated with two sessions of PRP while in the second group intravitreal ranibizumab was administered at the end of the first laser session. Intravitreal ranibizumab after PRP showed a larger reduction in total area $\left(\mathrm{mm}^{2}\right)$ of fluorescein leakage at week 48 compared with PRP.

In a similar study, Tonello et al ${ }^{95}$ showed no significant improvement in BCVA, but the total area of actively leaking NVs was significantly reduced in the PRP plus IVB group compared with the PRP group at weeks 4,9 , and $16(P<0.001)$. In this study, the bevacizumab was administered at the end of the second laser session. Cho et $a l^{89}$ examined the benefit of IVB before the PRP as an adjunctive treatment. In his study on 41 eyes with high-risk PDR patient, IVB was injected 1 week before initiating PRP. BCVA showed no change in the PRP 'Plus' group, whereas in the PRP group it was significantly worse at 3 months $(P=0.041)$. There was no significant change in BCVA in both groups when CME was evident. The number of eyes that developed vitreous haemorrhage was significantly lower in the 'Plus' group than in the PRP alone group $(P=0.023)$.

In conclusion, intravitreal anti-VEGF before and with PRP has great benefit in the treatment of high-risk PDR.

Anti-VEGF at the end of PRP treatment reduced fluorescein leakage in high-risk PDR: level of evidence III-3.

\section{Future treatment}

Regarding diabetic retinopathy, there are only studies on aflibercept and DME. ${ }^{97-99}$ There are no current studies on aflibercept and PDR.

\section{Conclusions}

The use of anti-VEGF agents in PDR is an evolving field. Although PRP is considered the first line for PDR, 
anti-VEGF drugs are slowly finding their place in the management of PDR. This is true especially in those cases when there is difficulty in performing PRP (such as vitreous haemorrhage and dense cataract) or when PRP has failed in preventing PDR progression.

For now, the existing indications for the use of antiVEGF agents in PDR include the following scenarios:

(1) Before vitrectomy (not more than 1 week) due to vitreous haemorrhage.

(2) Anterior segment neovascularization, preferably in those with an open angle.

(3) DME with PDR.

The disadvantages of anti-VEGF agents are their shortterm effect with reperfusion of abnormal vessels in time, TRD through fibrous contraction, and the infrequent risk of endophthalmitis. ${ }^{60}$ Importantly, the use of anti-VEGF agents for PDR remains off-label.

At present, there are no large, co-ordinated randomized trials into this area to demonstrate highlevel evidence. However, the above evidence can be used as a justification to treat PDR in specific indications to improve patient's outcome on a case-by-case basis when the practitioner is vigilant of the potential adverse effects. In the near future, results of ongoing trials such as the DRCR network 'Prompt Panretinal Photocoagulation Versus Ranibizumab plus Deferred Panretinal Photocoagulation for Proliferative Diabetic Retinopathy (Protocol S)' will provide relevant information. ${ }^{100}$

\section{References}

1 Zhang X, Saaddine JB, Chou CF, Cotch MF, Cheng YJ, Geiss LS et al. Prevalence of diabetic retinopathy in the United States, 2005-2008. JAMA 2010; 304: 649-656.

2 The Diabetic Retinopathy Study Research Group. Preliminary report on effects of photocoagulation therapy. Am J Ophthalmol 1976; 81: 383-396.

3 Fong DS, Aiello LP, Ferris 3rd FL, Klein R. Diabetic retinopathy. Diabetes Care 2004; 27: 2540-2553.

4 Witmer AN, Vrensen GF, Van Noorden CJ, Schlingemann RO. Vascular endothelial growth factors and angiogenesis in eye disease. Prog Retin Eye Res 2003; 22: 1-29.

5 Abu El-Asrar AM, Nawaz MI, Kangave D, Mairaj Siddiquei M, Geboes K. Angiogenic and vasculogenic factors in the vitreous from patients with proliferative diabetic retinopathy. J Diabetes Res 2013; 2013: 539658.

6 Kalka C, Masuda H, Takahashi T, Gordon R, Tepper O, Gravereaux E et al. Vascular endothelial growth factor (165) gene transfer augments circulating endothelial progenitor cells in human subjects. Circ Res 2000; 86: 1198-1202.

7 Li B, Sharpe EE, Maupin AB, Teleron AA, Pyle AL, Carmeliet $\mathrm{P}$ et al. VEGF and PIGF promote adult vasculogenesis by enhancing EPC recruitment and vessel formation at the site of tumor neovascularization. FASEB J 2006; 20: 1495-1497.
8 Aiello LP, Avery RL, Arrigg PG, Keyt BA, Jampel HD, Shah ST et al. Vascular endothelial growth factor in ocular fluid of patients with diabetic retinopathy and other retinal disorders. N Engl J Med 1994; 331: 1480-1487.

9 Wang X, Wang G, Wang Y. Intravitreous vascular endothelial growth factor and hypoxia-inducible factor 1a in patients with proliferative diabetic retinopathy. Am J Ophthalmol 2009; 148: 883-889.

10 Matsuoka M, Ogata N, Minamino K, Matsumura M. Expression of pigment epithelium-derived factor and vascular endothelial growth factor in fibrovascular membranes from patients with proliferative diabetic retinopathy. Jpn J Ophthalmol 2006; 50: 116-120.

11 Abu El-Asrar AM, Missotten L, Geboes K. Expression of hypoxia-inducible factor-1alpha and the protein products of its target genes in diabetic fibrovascular epiretinal membranes. Br J Ophthalmol 2007; 91: 822-826.

12 Lim JI, Spee C, Hinton DR. A comparison of hypoxiainducible factor- $\alpha$ in surgically excised neovascular membranes of patients with diabetes compared with idiopathic epiretinal membranes in nondiabetic patients. Retina 2010; 30: 1472-1478.

13 Chung EJ, Kang SJ, Koo JS, Choi YJ, Grossniklaus HE, Koh HJ. Effect of intravitreal bevacizumab on vascular endothelial growth factor expression in patients with proliferative diabetic retinopathy. Yonsei Med J 2011; 52 151-157.

14 Shibuya M. Differential roles of vascular endothelial growth factor receptor-1 and receptor-2 in angiogenesis. I Biochem Mol Biol 2006; 39: 469-478.

15 The Diabetic Retinopathy Study Research Group. Indications for photocoagulation treatment of diabetic retinopathy: Diabetic Retinopathy Study Report no. 14. Int Ophthalmol Clin 1987; 27: 239-253.

16 Vander JF, Duker JS, Benson WE, Brown GC, McNamara JA, Rosenstein RB. Long-term stability and visual outcome after favourable initial response of proliferative diabetic retinopathy to panretinal photocoagulation. Ophthalmology 1991; 98: 1575-1579.

17 Gentile RC, Stegman Z, Liebmann JM, Dayan AR, Tello C, Walsh JB et al. Risk factors for ciliochoroidal effusion after panretinal photocoagulation. Ophthalmology 1996; 103: 827-832.

18 McDonald HR, Schatz H. Macular edema following panretinal photocoagulation. Retina 1985; 5: 5-10.

19 Jardeleza MS, Miller JW. Review of anti-VEGF therapy in proliferative diabetic retinopathy. Semin Ophthalmol 2009; 24: 87-92.

20 Marshall J. The role of bevacizumab as first-line therapy for colon cancer. Semin Oncol 2005; 32(6 Suppl 9): S43-S47.

21 Abdallah W, Fawzi AA. Anti-VEGF therapy in proliferative diabetic retinopathy. Int Ophthalmol Clin 2009; 49: 95-107.

22 Hussain N, Ghanekar Y, Kaur I. The future implications and indications of anti-vascular endothelial growth factor therapy in ophthalmic practice. Indian J Ophthalmol 2007; 55: $445-450$.

23 Nguyen DH, Luo J, Zhang K, Zhang M. Current therapeutic approaches in neovascular age-related macular degeneration. Discov Med 2013; 15: 343-348.

24 NHMRC additional levels of evidence and grades for recommendations for developers of guidelines. Accessed September 2012. Available from http:// www.nhmrc. 
gov.au/files_nhmrc/file/guidelines/ stage_2_consultation _levels_and_grades.pdf.

25 Rizzo S, Genovesi-Ebert F, Bartolo E, Vento A, Miniaci S, Williams G. Injection of intravitreal bevacizumab (Avastin) as a preoperative adjunct before vitrectomy surgery in the treatment of severe proliferative diabetic retinopathy. Graefes Arch Clin Exp Ophthalmol 2008; 246: 837-842.

26 Chen E, Park $\mathrm{CH}$. Use of intravitreal bevacizumab as preoperative adjunct for tractional retinal detachment repair in severe proliferative diabetic retinopathy. Retina 2006; 26: 699-700.

27 Ishikawa K, Honda S, Tsukahara Y, Negi A. Preferable use of intravitreal bevacizumab as a pretreatment of vitrectomy for severe proliferative diabetic retinopathy. Eye (Lond) 2009; 23: 108-111.

28 Mishahi A, Roohiport R, Lashay A, Mohammadi SF, Abdoallahi A, Faghihi H. Bevacizumab augmented retinal laser photocoagulation in proliferative diabetic retinopathy: a randomized double-masked clinical trial. Eur J Ophthalmol 2008; 18: 263-269.

29 Spaide RF, Fisher YL. Intravitreal bevacizumab (Avastin) treatment of proliferative diabetic retinopathy complicated by vitreous hemorrhage. Retina 2006; 26: 275-278.

30 Arevalo JF, Garcia-Amaris RA. Intravitreal bevacizumab for diabetic retinopathy. Curr Diabetes Rev 2009; 5: 39-46.

31 Avery RL. Regression of retinal and iris neovascularization after intravitreal bevacizumab (Avastin) treatment. Retina 2006; 26: 352-354.

32 Avery RL, Pearlman J, Pieramici DJ, Rabena MD, Castellarin AA, Nasir MA et al. Intravitreal bevacizumab in the treatment of proliferative diabetic retinopathy. Ophthalmology 2006; 113: 1695-1715.

33 Hattori T, Shimada H, Nakashizuka H, Mizutani Y, Mori R, Yuzawa M. Dose of intravitreal bevacizumab (Avastin) used as preoperative adjunct therapy for proliferative diabetic retinopathy. Retina 2010; 30: 761-764.

34 Arevalo JF, Sanchez JG, Wu L, Maia M, Alezzandrini AA, Brito $\mathrm{M}$ et al. Pan-American Collaborative Retina Study Group. Primary intravitreal bevacizumab for diffuse diabetic macular edema. The Pan-American Collaborative Retina Study Group at 24 months. Ophthalmology 2009; 116: 1488-1497.

35 Lee SJ, Koh HJ. Enlargement of the foveal avascular zone in diabetic retinopathy after adjunctive intravitreal bevacizumab (Avastin) with pars plana vitrectomy. J Ocul Pharmacol Ther 2009; 25: 173-174.

36 Thew M. Rapid resolution of severe retinal neovascularisation in proliferative diabetic retinopathy following adjunctive intravitreal bevacizumab (Avastin). Clin Exp Optometry 2009; 92: 34-37.

37 Moradian S, Ahmadieh H, Malihi M, Soheilian M, Dehghan MH, Azarmina M. Intravitreal bevacizumab in active progressive proliferative diabetic retinopathy. Graefes Arch Clin Exp Ophthalmol 2008; 246: 1699-1705.

38 Mendrinos E, Donati G, Pournaras CJ. Rapid and persistent regression of severe new vessels on the disc in proliferative diabetic retinopathy after a single intravitreal injection of pegaptanib. Acta Ophthalmol 2009; 87: 683-684.

39 Adamis AP, Altaweel M, Bressler NM, Cunningham Jr ET, Davis MD, Goldbaum M et al. Macugen Diabetic Retinopathy Study Group. Changes in retinal neovascularization after pegaptanib (Macugen) therapy in diabetic individuals. Ophthalmology 2006; 113: 23-28.
40 Minnella AM, Savastano CM, Ziccardi L, Scupola A, Falsini B, Balestrazzi E. Intravitreal bevacizumab (Avastin) in proliferative diabetic retinopathy. Acta Ophthalmol 2008; 86: 683-687.

41 Schmidinger G, Maar N, Bolz M, Scholda C, Schmidt-Erfurth U. Repeated intravitreal bevacizumab treatment of persistent new vessels in proliferative diabetic retinopathy after complete panretinal photocoagulation. Acta Ophthalmol 2011; 89: 76-81.

42 Torres-Soriano ME, Reyna-Castelan E, Hernandez- Rojas M. Tractional retinal detachment after intravitreal injection of bevacizumab in proliferative diabetic retinopathy. Retinal Cases Brief Rep 2009; 3: 70-73.

43 Yeh PT, Yang CM, Lin YC, Chen MS, Yang CH. Bevacizumab pretreatment in vitrectomy with silicone oil for severe diabetic retinopathy. Retina 2009; 29: 768-774.

44 Jonas JB, Schmidbauer M, Rensch F. Progression of tractional retinal detachment following intravitreal bevacizumab. Acta Ophthalmol 2009; 87: 571-572.

45 Arevalo JF, Maia M, Flynn Jr HW, Saravia M, Avery RL, $\mathrm{Wu} \mathrm{L}$, Eid Farah $\mathrm{M}$ et al. Tractional retinal detachment following intravitreal bevacizumab (Avastin) in patients with severe proliferative diabetic retinopathy. Br J Ophthalmol 2008; 92: 213-216.

46 Jalil A, Fenerty C, Charles S. Intravitreal bevacizumab (Avastin) causing acute glaucoma: an unreported complication. Eye (Lond) 2007; 21: 1541.

47 Kuiper EJ, Van Nieuwenhoven FA, de Smet MD, van Meurs JC, Tanck MW, Oliver N et al. The angio-fibrotic switch of VEGF and CTGF in proliferative diabetic retinopathy. PLoS One 2008; 3: e2675.

48 Oshima Y, Shima C, Wakabayashi T, Kusaka S, Shiraga F, Ohji $\mathrm{M}$ et al. Microincision vitrectomy surgery and intravitreal bevacizumab as a surgical adjunct to treat diabetic traction retinal detachment. Ophthalmology 2009; 116: 927-938.

49 Krishnan R, Goverdhan S, Lochhead J. Intravitreal pegaptanib in severe proliferative diabetic retinopathy leading to the progression of tractional retinal detachment. Eye (Lond) 2009; 23: 1238-1239.

50 Ahmadieh H, Shoeibi N, Entezari M, Monshizadeh R. Intravitreal bevacizumab for prevention of early postvitrectomy hemorrhage in diabetic patients: a randomized clinical trial. Ophthalmology 2009; 116: 1943-1948.

51 Arevalo JF, Sanchez JG, Lasave AF, Wu L, Maia M, Bonafonte $\mathrm{S}$ et al. Intravitreal bevacizumab (Avastin) for diabetic retinopathy: the 2010 GLADAOF lecture. J Ophthalmol 2011; 2011: 584238.

52 Goel N, Kumar V, Ghosh B. Ischemic maculopathy following intravitreal bevacizumab for refractory diabetic macular edema. Int Ophthalmol 2011; 31: 39-42.

53 Michaelides M, Fraser-Bell S, Hamilton R, Kaines A, Egan C, Bunce $\mathrm{C}$ et al. Macular perfusion determined by fundus fluorescein angiography at the 4-month time point in a prospective randomized trial of intravitreal bevacizumab or laser therapy in the management of diabetic macular edema (Bolt Study): Report 1. Retina 2010; 30: 781-786.

54 Frenkel RE, Mani L, Toler AR, Frenkel MP. Intraocular pressure effects of pegaptanib (Macugen) injections in patients with and without glaucoma. Am J Ophthalmol 2007; 143: 1034-1035. 
55 Wu L, Martínez-Castellanos MA, Quiroz-Mercado H, Arevalo JF, Berrocal MH, Farah ME et al. Pan American Collaborative Retina Group (PACORES). Twelve-month safety of intravitreal injections of IVB (Avastin): results of the Pan-American Collaborative Retina Study Group (PACORES). Graefes Arch Clin Exp Ophthalmol 2008; 246: 81-87.

56 Gandhi JS, Tan LT, Pearce I, Charles SJ. Bevacizumab (Avastin) as a surgical adjunct in diabetic vitrectomy for fibrovascular disease. Eye 2009; 23: 742-743.

57 Mitamura Y, Ogata K, Oshitari T, Asaumi N, Yamamoto S. Retinal detachment with macular hole following intravitreal bevacizumab in patients with severe proliferative diabetic retinopathy. Br J Ophthalmol 2008; 92: 717-718.

58 Ladas ID, Karagiannis DA, Rouvas AA, Kotsolis AI, Liotsou A, Vergados I. Safety of repeat intravitreal injections of IVB versus ranibizumab: our experience after 2,000 injections. Retina 2009; 29: 313-318.

59 Nishijima K, Ng YS, Zhong L, Bradley J, Schubert W, Jo N et al. Vascular endothelial growth factor-A is a survival factor for retinal neurons and a critical neuroprotectant during the adaptive response to ischemic injury. Am J Pathol 2007; 171: 53-67.

60 Saint-Geniez M, Maharaj AS, Walshe TE, Tucker BA, Sekiyama E, Kurihara T et al. Endogenous VEGF is required for visual function: evidence for a survival role on Müller cells and photoreceptors. PLoS One 2008; 3: e3554.

61 D'Amore PA. Vascular endothelial cell growth factor-A: not just for endothelial cells anymore. Am J Pathol 2007; 171: 14-18.

62 Maharaj AS, D'Amore PA. Roles for VEGF in the adult. Microvasc Res 2007; 74: 100-113.

63 Fagan XJ, Al-Qureshi S. Intravitreal injections: a review of the evidence for best practice. Clin Exp Ophthalmol 2013; 41: 500-507.

64 Googe J, Brucker AJ, Bressler NM, Qin H, Aiello LP, Antoszyk A et al. The Diabetic Retinopathy Clinical Research Network. Randomized trial evaluating short term effects of intravitreal Ranibizumab or Triamcinolone acetonide on macular edema after focal/grid laser for diabetic macular edema in eyes also receiving panretinal photocoagulation. Retina 2011; 31: 1009-1027.

65 Rosenfeld PJ, Brown DM, Heier JS, Boyer DS, Kaiser PK, Chung CY et al. MARINA Study Group. Ranibizumab for neovascular age-related macular degeneration. $N$ Engl J Med 2006; 355: 1419-1431.

66 CATT Research GroupMartin DF, Maguire MG, Ying GS, Grunwald JE, Fine SL, Jaffe GJ. Ranibizumab and bevacizumab for neovascular age-related macular degeneration. N Engl J Med 2011; 364: 1897-1908.

67 Gragoudas ES, Adamis AP, Cunningham Jr ET, Feinsod M, Guyer DR. Pegaptanib for neovascular age-related macular degeneration. N Engl J Med 2004; 351: 2805-2816.

68 Roth DB, King A, Weiss M, Klein D. Systemic adverse events after bevacizumab. Ophthalmology 2009; 116: 1226.

69 Brown DM, Nguyen QD, Marcus DM, Boyer DS, Patel S, Feiner L et al. RIDE and RISE Research Group. Long-term outcomes of ranibizumab therapy for diabetic macular edema: the 36-month results from two phase III trials: RISE and RIDE. Ophthalmology 2013; 120: 2013-2022.

70 D'Amico DJ, Masonson HN, Patel M, Adamis AP, Cunningham Jr ET, Guyer DR et al. VEGF Inhibition Study in Ocular Neovascularization (V.I.S.I.O.N.) Clinical Trial
Group. Pegaptanib sodium for neovascular age related macular degeneration. Two-year safety results of the two prospective, multicenter, controlled clinical trials. Ophthalmology 2006; 113: 992-1001.

71 Singerman LJ, Masonson H, Patel M, Adamis AP, Buggage R, Cunningham E et al. Pegaptanib sodium for neovascular age-related macular degeneration: third-year safety results of the VEGF inhibition study in ocular neovascularisation (VISION) trial. Br J Ophthalmol 2008; 92: 1606-1611.

72 Campbell RJ, Bell CM, Campbell Ede L, Gill SS. Systemic effects of intravitreal vascular endothelial growth factor inhibitors. Curr Opin Ophthalmol 2013; 24: 197-204.

73 Costagliola C, Cipollone U, Rinaldi M, della Corte M, Semeraro F, Romano MR. Intravitreal bevacizumab (Avastin) injection for neovascular glaucoma: a survey on 23 cases throughout 12-month follow-up. Br J Clin Pharmacol 2008; 66: 667-673.

74 Chalam KV, Gupta SK, Grover S, Brar VS, Agarwal S. Intracameral Avastin dramatically resolves iris neovascularization and reverses neovascular glaucoma. Eur J Ophthalmol 2008; 18: 255-262.

75 Lim TH, Bae SH, Cho YJ, Lee JH, Kim HK, Sohn YH. Concentration of vascular endothelial growth factor after intracameral bevacizumab injection in eyes with neovascular glaucoma. Korean J Ophthalmol 2009; 23: 188-192.

76 Eid TM, Radwan A, el-Manawy W, el-Hawary I. Intravitreal bevacizumab and aqueous shunting surgery for neovascular glaucoma: safety and efficacy. Can J Ophthalmol 2009; 44: 451-456.

77 Jonas BJ, Libondi T, Baltz S, Vossmerbaeumer U. Intravitreal bevacizumab for vitreous haemorrhage. Acta Ophthalmol 2008; 86: 585-586.

78 Huang YH, Yeh PT, Chen MS, Yang CH, Yang CM. Intravitreal bevacizumab and panretinal photocoagulation for proliferative diabetic retinopathy associated with vitreous hemorrhage. Retina 2009; 29: 1134-1140.

79 Diabetic Retinopathy Clinical Research Network. Randomized clinical trial evaluating intravitreal ranibizumab or saline for vitreous hemorrhage from proliferative diabetic retinopathy. JAMA Ophthalmol 2013; 131: 283-293.

80 Krzystolik MG, Filippopoulos T, Ducharme JF, Loewenstein JI. Pegaptanib as an adjunctive treatment for complicated neovascular diabetic retinopathy. Arch Ophthalmol 2006; 124: 920-921.

81 Smith JM, Steel DH. Anti-vascular endothelial growth factor for prevention of postoperative vitreous cavity haemorrhage after vitrectomy for proliferative diabetic retinopathy. Cochrane Database Syst Rev 2011; (5): CD008214.

82 Ahn J, Woo SJ, Chung H, Park KH. The effect of adjunctive intravitreal bevacizumab for preventing post vitrectomy hemorrhage in proliferative diabetic retinopathy. Ophthalmology 2011; 118: 2218-2226.

83 Zhao LQ, Zhu H, Zhao PQ, Hu YQ.A. Systematic review and meta-analysis of clinical outcomes of vitrectomy with or without intravitreal bevacizumab pretreatment for severe diabetic retinopathy. Br J Ophthalmol 2011; 95: 1216-1222.

84 Early Treatment Diabetic Retinopathy Study Research Group. Early photocoagulation for diabetic retinopathy. 
ETDRS report number 9. Ophthalmology 1991; 98(5 Suppl): 766-785.

85 Myers SM. Macular edema after scatter laser photocoagulation for proliferative diabetic retinopathy. Am J Ophthalmol 1980; 90: 210-216.

86 McDonald HR, Schatz H. Visual loss following panretinal photocoagulation for proliferative diabetic retinopathy. Ophthalmology 1985; 92: 388-393.

87 Shimura M, Yasuda K, Nakazawa T, Kano T, Ohta S, Tamai M. Quantifying alterations of macular thickness before and after panretinal photocoagulation in patients with severe diabetic retinopathy and good vision. Ophthalmology 2003; 110: 2386-2394.

88 Filho JA, Messias A, Almeida FP, Ribeiro JA, Costa RA, Scott IU et al. Panretinal photocoagulation (PRP) versus PRP plus intravitreal ranibizumab for high-risk proliferative diabetic retinopathy. Acta Ophthalmol 2011; 89: 567-572.

89 Cho WB, Oh SB, Moon JW, Kim HC. Panretinal photocoagulation combined with intravitreal bevacizumab in high-risk proliferative diabetic retinopathy. Retina 2009; 29: 516-522.

90 Flynn Jr HW, Chew EY, Simons BD, Barton FB, Remaley NA, Ferris 3rd FL. Pars plana vitrectomy in the Early Treatment Diabetic Retinopathy Study. ETDRS report number 17. The Early Treatment Diabetic Retinopathy Study Research Group. Ophthalmology 1992; 99: 1351-1357.

91 Erdol H, Turk A, Akyol N, Imamoglu HI. The results of intravitreal bevacizumab injections for persistent neovascularizations in proliferative diabetic retinopathy after photocoagulation therapy. Retina 2010; 30: 570-577.

92 Cintra LP, Costa RA, Ribeiro JA, Calucci D, Scott IU, Messias A et al. Intravitreal bevacizumab (Avastin) for persistent new vessels in diabetic retinopathy (IBEPE study): 1-year results. Retina 2013; 33: 1109-1116.

93 Jorge R, Costa RA, Calucci D, Cintra LP, Scott IU. Intravitreal bevacizumab (Avastin) for persistent new vessels in diabetic retinopathy (Ibepe study). Retina 2006; 26: 1006-1013.

94 Yang CM, Yeh PT, Yang CH, Chen MS. Bevacizumab pretreatment and long-acting gas infusion on vitreous clear-up after diabetic vitrectomy. Am J Ophthalmol 2008; 146: 211-217.

95 Tonello M, Costa RA, Almeida FP, Barbosa JC, Scott IU, Jorge R. Panretinal photocoagulation versus PRP plus intravitreal bevacizumab for high risk proliferative diabetic retinopathy (IBeHi study). Acta Ophthalmol 2008; 86: 385-389.

96 Mason JO, Yunker JJ, Vail R, McGwin Jr G. Intravitreal bevacizumab (Avastin) prevention of panretinal photocoagulation induced complications in patients with severe proliferative diabetic retinopathy. Retina 2008; 28 : 1319-1324.

97 Do DV, Schmidt-Erfurth U, Gonzalez VH, Gordon CM, Tolentino M, Berliner AJ et al. The DA VINCI study: phase 2 primary results of VEGF Trap-Eye in patients with diabetic macular edema. Ophthalmology 2011; 118: 1819-1826.

98 Do DV, Nguyen QD, Boyer D, Schmidt-Erfurth U, Brown $\mathrm{DM}$ et al. DA VINCI Study Group. One-year outcomes of the DA VINCI study of VEGF Trap-Eye in eyes with diabetic macular edema. Ophthalmology 2012; 119: 1658-1665.

99 Clinicaltrials.gov. Diabetic Retinopathy Clinical Research Network. Comparative Effectiveness Study of Intravitreal Aflibercept, Bevacizumab, and Ranibizumab for DME. ClinicalTrial.gov Identifier NCT01627249. http:/ / clinicaltrials.gov/ct2/show/NCT01627249. Accessed 15 October 2012. II.

100 Prompt Panretinal Photocoagulation Versus Ranibizumab plus Deferred Panretinal Photocoagulation for Proliferative Diabetic Retinopathy (Protocol S) http:/ / clinicaltrials.gov/show/NCT01489189. Accessed on 24 May 2013. 